\section{References}

1. Venuta F, Rendina EA, Coloni GF. Surgery of the superior vena cava: resection and reconstruction. CTSnet 2003. Available at: www.ctsnet. org/sections/clinicalresources/thoracic/expert_tech-6.html. Accessed 22 October 2003.

2. Rendina EA, Venuta F, De Giacomo T, Ciccone AM, Moretti M, Ruvolo G, et al. Sleeve resection and prosthetic reconstruction of the pulmonary artery for lung cancer. Ann Thorac Surg. 1999;68:9951002.
3. D'Andrilli A, Ibrahim M, Venuta F, De Giacomo T, Coloni GF, Rendina EA. Glutaraldehyde preserved autologous pericardium for patch reconstruction of the pulmonary artery and superior vena cava. Ann Thorac Surg. 2005;80:357-8.

4. Piccione W, Penfield Faber L, Warren WH. Superior vena cava reconstruction using autologous pericardium. Ann Thorac Surg. 1990;50:417-9.

5. Spaggiari L, Galetta D, Veronesi G, Leo F, Gasparri R, Petrella F, et al. Superior vena cava replacement for lung cancer using a heterologous (bovine) prosthesis: preliminary results. J Thorac Cardiovasc Surg. 2006;131:491-2.

\title{
Atriocaval laceration presenting as delayed pericardial tamponade
}

\author{
Forrest 0. Moore, MD, ${ }^{a}$ John D. Berne, MD, ${ }^{a}$ Gerard J. Fulda, MD, ${ }^{\mathrm{b}}$ Adam D. Fox, D0, \\ Glen H. Tinkoff, MD, ${ }^{\mathrm{b}}$ Allen L. Davies, MD, ${ }^{\mathrm{b}}$ and Kathleen McNicholas, MD, ${ }^{\mathrm{b}}$ Tyler, Tex \\ and Newark, Del
}

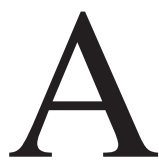
triocaval injuries are rare and usually manifest in patients presenting in extremis. Delayed complications are even more uncommon. This case documents delayed pericardial tamponade in a patient with an atriocaval laceration.

\section{Clinical Summary}

A 39-year-old man was struck in the anterior chest by a large metal beam. The patient was hemodynamically stable with a pulse rate of 106 beats/min. Chest radiograph was normal, and a focused assessment for the sonography in trauma was negative for pericardial fluid. Computed tomography scan of the chest was unremarkable.

The patient was admitted to the intensive care unit, and a transthoracic echocardiogram revealed a normal ejection fraction and no pericardial effusion. He was extubated on hospital day 2, and the chest tube was removed on hospital day 5 . He was discharged the following day. Physical examination and chest radiograph results were normal 1 week after discharge.

Two weeks later the patient presented to the cardiologist with a 2-day history of shortness of breath. A transthoracic echocardiogram demonstrated a large pericardial effusion.

From the Division of Trauma and Surgical Critical Care, East Texas Medical Center, ${ }^{a}$ Tyler, Tex, and Department of Surgery, Christiana Care Health System, ${ }^{\mathrm{b}}$ Newark, Del.

Received for publication Feb 27, 2006; accepted for publication March 15, 2006.

Address for reprints: Forrest O. Moore, MD, Division of Trauma and Surgical Critical Care, East Texas Medical Center, 1020 E. Idel, Tyler, TX 75701 (E-mail: moore677@aol.com).

J Thorac Cardiovasc Surg 2006;132:194-5

$0022-5223 / \$ 32.00$

Copyright $\odot 2006$ by The American Association for Thoracic Surgery doi:10.1016/j.jtcvs.2006.03.022
The cardiothoracic surgery department was consulted, and the patient was taken to the operating room. A median sternotomy was performed, followed by a pericardiectomy for a tense hemopericardium.

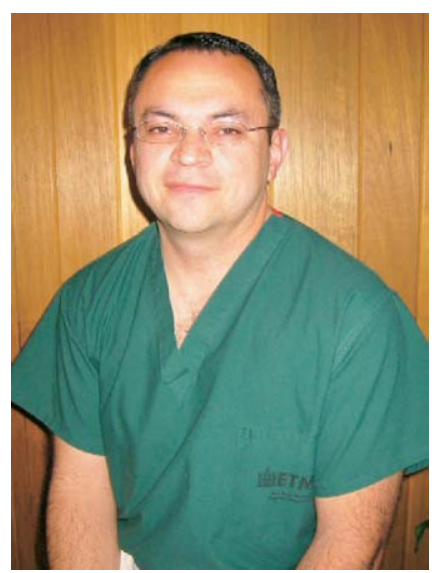

Dr Moore Further examination revealed a thrombus in the region of the inferior vena cava-atrial junction and a partial-thickness injury (Figure 1). Because of the injury location and the need for repair, the patient was placed on cardiopulmonary bypass. Multiple pledgeted sutures were used to close the partialthickness defect.

The patient's postoperative course was uncomplicated. He was extubated on postoperative day 2 , the chest tubes were removed on postoperative day 3 , and he was discharged on postoperative day 6 .

The patient was reevaluated on postoperative day 16 and was recovering uneventfully.

\section{Discussion}

Intrapericardial great vessel injury is a rare occurrence, accounting for a small fraction of the $25 \%$ of trauma deaths that are the result of thoracic injuries. ${ }^{1}$ Although the incidence of atriocaval injury is unknown, Fulda and colleagues ${ }^{2}$ reported 59 patients with ruptures of the heart and/or pericardium, 7 of whom had atriocaval junction disruption. The survival from atriocaval injuries, once routinely fatal, has been improved with rapid transport to trauma centers and rapid diagnosis. Yet, $50 \%$ of patients die before reaching the hospital, whereas $50 \%$ of the remainder die despite treatment. ${ }^{3,4}$

Most documented cases of atriocaval injury manifest immediately as hemopericardium with pericardial tamponade, if not already having proven fatal from exsanguinations caused by associated pericardial disruption or associated injuries. Differential diagnosis should include pericardial tamponade from intrapericardial great vessel injury in a patient with refractory hypotension and shock, especially without obvious blood loss. 


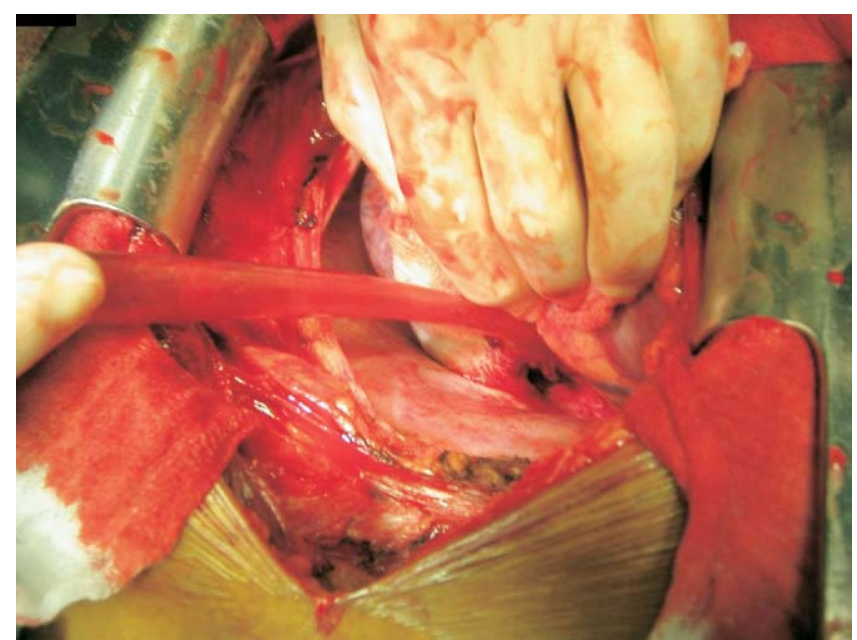

Figure 1. Intraoperative photograph shows a partial-thickness laceration with clot at the atriocaval junction.

The chest radiograph is the initial diagnostic tool in evaluating blunt chest trauma. The gold standard for diagnosis of aortic injury is aortography, although dynamic helical computed tomography scanning has documented sensitivity equal to aortography and can demonstrate pericardial fluid. Surgeon-performed focused assessment for the sonography in trauma examination is considered the test of choice for rapid screening. Transesophageal echocardiography is an additional diagnostic tool but is not always readily available, and the entire thoracic aorta is not well visualized with this technique.
Once the injury is diagnosed, a median sternotomy should be performed. Cardiopulmonary bypass should be considered with repair and reconstruction of these injuries, especially because bleeding can be significant.

Our case documents the rare occurrence of delayed pericardial tamponade 3 weeks after injury. The delay in presentation was most likely because of a clot forming over a partial-thickness tear at the atriocaval junction. Tamponade occurred either from slow bleeding into the pericardial space over the course of 3 weeks or a sudden displacement of the temporary clot at the atriocaval wound.

This case reiterates the need for physicians to be continually aware of late complications after blunt chest trauma. Interval follow-up examination of all patients with significant chest trauma is highly recommended and should be continued for several months after such trauma. The clinical examination should then direct one to obtain further diagnostic studies. These patients must also be instructed to return immediately when chest pain or shortness of breath occurs.

We thank Douglas Bugel, medical photographer, and Cynthia J. Clendenin, medical editor, at Christiana Care Health System for their assistance with our article.

\section{References}

1. Clements RH, Fisher PJ 2nd. Blunt injury of the intrapericardial great vessels. J Trauma. 2001;50:129-32.

2. Fulda G, Brathwaite CEM, Rodriguez A, Turney SZ, Dunham CM, Cowley RA. J Trauma. 1991;31:167-73.

3. Tochii M, Sugimura S, Iriyama T, et al. Blunt rupture of the intrapericardial inferior vena cava: report of two cases. Kyobu Geka. 2000;53: 145-7.

4. Peitzman AB, Udekwu AO, Pevec W, Albrink M. Transection of the inferior vena cava from blunt thoracic trauma: case reports. J Trauma. 1989;29:534-6. 